\title{
RELIGIOSIDAD Y ACTITUDES ANTE LA MUERTE EN LA MONTAÑA NOROCCIDENTAL LEONESA: EL CONCEJO DE LACIANA EN EL SIGLO XVIII
}

\author{
Alfredo MARTÍN GARCÍA \\ Universidad de León
}

\begin{abstract}
RESUMEN: El estudio de los testamentos dieciochescos del concejo de Laciana, nos muestra unos comportamientos de los lacianiegos ante la muerte muy similares a lo observado para otras zonas del reino de León. De igual modo, las fuentes nos han permitido constatar el importante desarrollo del asociacionismo seglar durante la segunda mitad de siglo, así como la fuerte impronta de determinadas devociones marianas autóctonas, como la Virgen del Rosario de Robles, la de Carreras y la de Carrasconte o de otras pasionales como el Cristo de Veracruz.
\end{abstract}

PALABRAS CLAVE: Laciana, León, Historia de las mentalidades, religiosidad barroca, siglo XVIII.

ABSTRACT: The study of the testators of Laciana municipality during $18^{\text {th }}$ century, shows similars behaviours before death than other areas of the Kingdom of León. Likewise, the sources show an important growth in the number of brotherhoods along the second half of this century. We can see the importance of some devotions, like Our Lady of Rosary, Our Lady of Carreras, Our Lady of Carrasconte or the Christ of Veracruz.

KEYWORDS: Laciana, León, History of Mentality, Baroque religiousness, $18^{\text {th }}$ century.

\section{CONTEXTUALIZACIÓN DE LA ZONA A ESTUDIAR Y OBJETI- VOS}

La comarca de Laciana está situada en el noroeste de la actual provincia de León, en plena Cordillera Cantábrica, entre los términos municipales de Palacios del Sil, Babia, Omaña y el principado de Asturias. Su extensión territorial es de $217 \mathrm{Km}^{2}$, estableciéndose las distintas entidades poblacionales que la componen entre los 900 y los 1.300 metros de altitud. Estos asentamientos humanos huyen de las zonas más abruptas del territorio, aprovechando los pequeños y encajonados 
valles fluviales tributarios del río Sil que lo surcan ${ }^{1}$. Las condiciones de la orografía, el clima o la altitud, determinaron en gran medida el tipo de economía que imperaba en la zona durante el Antiguo Régimen. Es cierto que Laciana ofrecía importantes recursos naturales, como los extensos pastizales para el ganado o los espesos bosques y caudalosos ríos, que facilitaban las actividades cinegéticas. Pero, en contraposición a estas indudables ventajas, se encontraban las dificultades halladas para el desarrollo de una agricultura de rendimientos aceptables. Las elevadas pendientes y los suelos poco profundos, es decir, de baja calidad, contribuían decisivamente a configurar un sistema agrícola dominado por el centeno, cuyos bajos rendimientos solamente podían orientarse hacia la subsistencia $^{2}$. El otro pilar económico era la ganadería, ya que las extensas zonas de pasto común permitían la manutención de un número importante de reses de forma gratuita, sin resentimiento alguno para las economías familiares. De entre todas las cabañas destacaba la menuda, sobre todo la ovina, si bien la bovina desempeñaba también un papel importante.

Las discretas expectativas económicas de los lacianiegos en su propia tierra, explican la presencia constante a lo largo de todo el período moderno de la emigración como alternativa, bien temporal o bien definitiva, a ese problema ${ }^{3}$. Y es que estamos ante una sociedad marcadamente agrícola, en la que los grandes y medianos propietarios no alcanzaban siquiera el $10 \%$ del conjunto vecinal y en donde más de la mitad de sus vecinos vivían en los límites de la subsistencia ${ }^{4}$. De hecho, la polarización entre ricos y pobres se fue agudizando cada vez más a lo largo del siglo XVIII, etapa expansiva desde el punto de vista agrícola y demográfico ${ }^{5}$.

Desde el punto de vista administrativo, el concejo de Laciana durante la Edad Moderna estaba integrado en el partido de León, uno de los dos en los que se

${ }^{1}$ Agradecemos a la profesora María José Pérez Álvarez su inestimable colaboración para el estudio de una zona que ella conoce como nadie.

2 PÉREZ, Ma.J. (1996). La montaña noroccidental leonesa en la Edad Moderna. León: Universidad de León, pp. 113 y ss.

3 PÉREZ, M M.J. (2004). «Familia y estrategias familiares en el marco de unas estructuras socioeconómicas tradicionales: el modelo de la montaña noroccidental leonesa en la Edad Moderna». Revista de Demografía Histórica, pp. 121-147, p. 126.

${ }^{4}$ PÉREZ, Ma.J. (1996). La montaña noroccidental..., pp. 396 y ss.

${ }^{5}$ Las pequeñas explotaciones agrícolas pasaron de representar el 48,6\% del total en 1710 al $75 \%$ a comienzos del XIX. PÉREZ, Ma.J. (2004). «Familia y estrategias familiares...»»p. 126. 
dividió el reino leonés hasta la llegada del régimen liberal ${ }^{6}$. Los condes de Luna eran los señores del territorio, si bien los lacianiegos estuvieron casi constantemente enfrentados a ellos, a través de la vía judicial, respondiendo de esta manera a los ilegales atropellos y usurpaciones de los nobles en cuestiones tan importantes como el de los puertos ${ }^{7}$. Sin embargo, y a pesar de la inclusión del territorio dentro del reino de León, desde el punto de vista espiritual, Laciana estaba integrada en el obispado de Oviedo. Estamos pues ante un mundo marcado por la tradición y la pobreza, un mundo alejado de los centros de decisión política de la monarquía o de la autoridad diocesana, pero no por ello absolutamente aislado, gracias a la labor de conexión ejercida por los movimientos migratorios.

El objetivo de este trabajo es complementar el conocimiento que ya se tiene de la zona desde el punto de vista demográfico, social y económico, a través de un campo de investigación todavía virgen: el mundo de las mentalidades. Nuestra pretensión es pues realizar un acercamiento al universo devocional y a las actitudes ante la muerte de los lacianiegos durante el siglo XVIII. La inexistencia de trabajos de esta índole para la zona justifican ya de por sí la necesidad de un estudio de estas características. Pero, además, las peculiaridades propias de Laciana, como espacio de montaña a priori especialmente apto para la localización de comportamientos poco ortodoxos desde el punto de vista religioso o moral, acentúan aún más nuestro interés: queremos conocer si Laciana en el siglo XVIII formaba parte de esas "Indias de Europa" que tanto obsesionaban a los misioneros postridentinos o, por el contrario, presentaba unos comportamientos similares a su entorno más inmediato, tanto Asturias como el propio reino de León.

Para alcanzar ese objetivo hemos optado por el testamento como principal recurso documental. En cuanto al método, como no podía ser de otra manera, el elegido es aquel iniciado hace ya varias décadas por Michel Vovelle, a quien corresponde el acierto de emplear por vez primera el tratamiento serial de los testamentos para extraer conclusiones de carácter cuantitativo. Las virtudes del testamento para el estudio de las mentalidades religiosas y la muerte son, a estas

${ }^{6}$ El reino de León se dividía durante toda la Edad Moderna en dos partidos: el de León y el de Ponferrada. Rubio, L.M. (1993). El sistema político concejil en la provincia de León. León: Universidad de León, p. 28.

${ }^{7}$ PÉREZ, Ma .J. (1997). «Los pleitos sostenidos por el concejo de Laciana contra el conde de Luna durante el reinado de Carlos I»». Estudios Humanísticos, pp. 75-85, p.76. 
alturas, de todos conocidas ${ }^{8}$. El testamento durante la época no sólo refleja el interés del testador por dejar bien amarrados los asuntos de la vida terrena, sino que se preocupa muy especialmente por facilitarle una buena muerte, esto es, por el futuro de su alma. Desde ese punto de vista, este tipo de documentación resulta un eficaz instrumento para introducirnos en un campo tan complejo. Pero también, la proliferación de trabajos basados en esta documentación en las últimas décadas, nos han enseñado a marcar nítidamente sus deficiencias. Por su propia naturaleza, el documento esconde ciertas conductas jurídicas que, por serlo, son tópicas y normalizadas y de las que es harto complicado extraer información útil $1^{9}$. Por otro lado, no podemos olvidar que el testamento es una fuente significativamente más rica en información a medida que escalamos en la pirámide social: no es pues una fuente muy "democrática" y eso redunda negativamente en el conocimiento de los comportamientos de las clases populares. Además, la presencia de este tipo de escritura es más abundante en el medio urbano que en el rural, a pesar de que parece que a lo largo del siglo XVIII se atisba un lento avance también en el campo ${ }^{10}$.

Por todo lo dicho no es recomendable el uso exclusivo de este tipo de fuente para un estudio de mentalidades. Es necesario manejar también otros canales de información complementarios que contribuyan a enriquecer nuestra visión: libros sacramentales, libros de visitas, documentación generada por cofradías, constituciones sinodales, literatura devocional, etc. Lamentablemente, para el caso que nos ocupa, estas alternativas documentales son muy limitadas. Por ejemplo, los libros sacramentales muestran una serie de deficiencias muy notables, los de visitas y cofradías, en la mayoría de los casos, han desaparecido y, como es natural, en una zona como la que nos ocupa no existen obras devocionales específicas. Aún así, intentaremos a través de lo poco que ha llegado a nuestros días, complementar la información extraída de los testamentos.

${ }^{8}$ Ver, EIRAS, A. (1981) «Tipología documental de los protocolos gallegos». EIRAS, A. y colaboradores. La historia social de Galicia en sus fuentes de protocolos. Santiago de Compostela: Universidad de Santiago, pp. 21-113.

9 SÁnCHEZ, J.L. (1993). «La histeria religiosa del Barroco en la norma de la historia de las mentalidades: reflexiones para una apertura». Álvarez, L.C. y CREMADES, C.M. (Eds.). Mentalidad e ideología en el Antiguo Régimen. Murcia: Universidad de Murcia, p. 120.

${ }^{10}$ Dadas las carencias de los libros sacramentales de la zona, aprovecharemos las conclusiones extraídas por el profesor Barreiro Mallón sobre la vecina montaña asturiana. BARREIRO, B. (1984). «La nobleza asturiana ante la muerte y la vida». La documentación notarial y su historia (actas del II Coloquio de Metodología Histórica Aplicada). Salamanca: Universidad de Santiago, pp. 27-60, p. 29. 


\section{LOS LACIANIEGOS ANTE LA MUERTE}

La muerte ha sido desde siempre una de las principales preocupaciones del ser humano. Esa constante inquietud desde que el hombre es hombre, no implica, ni mucho menos, que su imagen y la actitud de la sociedad ante ella se hayan mantenido inalterables a lo largo de los siglos. Ariès ha constatado el paulatino arrinconamiento de la idea de la muerte desde su constante y cotidiana presencia en la Edad Media hasta nuestros días, en los que ha pasado a convertirse en un tema tabú $^{11}$. Durante el siglo XVIII en la Europa del Antiguo Régimen, la muerte estaba muy presente en el día a día. El régimen demográfico venía marcado por unas tasas de mortalidad ordinaria muy superiores a las actuales, a lo que había que añadir los devastadores efectos de la mortalidad extraordinaria que, con cierta frecuencia, se presentaba en forma de brote epidémico, diezmando la población ${ }^{12}$. A estos efectos relacionados con las enfermedades, la mala alimentación o la falta de higiene, hay que añadir el influjo de la violencia en una sociedad en la que hasta la propia justicia no tenía el menor reparo en ensañarse sádicamente con el reo condenado a la pena capital.

La muerte pues, formaba parte mucho más intensamente que en nuestros días, de la vida cotidiana, ya no sólo por la impronta de las epidemias o la violencia, sino también por su estrecha relación con las creencias religiosas del momento. Durante el siglo XVIII, la sociedad española, y por ende la lacianiega, se hallaba profundamente influida por la religiosidad barroca emanada de la Reforma católica. Ante una visión marcadamente pesimista del mundo como la que propugnaba Trento, el hombre se aferraba a la esperanza en otra vida en la que el bien triunfara frente a un mal demasiado presente en la terrena ${ }^{13}$. Pero esa esperanza contrastaba con el temor al tremendo día del Juicio o a los terribles suplicios del Purgatorio. El ser humano, en sus últimos instantes de vida, podía salvarse a través de un verdadero arrepentimiento, o condenarse irremisiblemente para la eternidad. Se trataba de un momento crucial y, por ello, como refleja la práctica totalidad de los testamentos consultados, el temor a la muerte se convertía en "cosa natural a toda criatura bibiente" ${ }^{14}$. Esa "hora de la verdad" que suponía el

${ }^{11}$ ARIES, P. (1975). Essais sur l'histoire de la mort en Occident du Moyen Age à nos jours. París: Du Seuil, pp. 25 y ss.

12 PÉREZ, Ma.J. (1996). La montaña noroccidental..., pp. 294-195.

${ }^{13}$ De La Pascua, Ma.J. (1984). Actitudes ante la muerte en el Cádiz de la primera mitad del siglo XVIII. Cádiz: Diputación provincial, p. 51.

14 Testamento de Inés Álvarez (1734). A.H.P.L. (Archivo Histórico Provincial de León), Protocolos notariales de Murias de Paredes, Escribano Gabriel Álvarez, Caj. 6.554. 
óbito, explica la importancia de las últimas voluntades del moribundo que, como veremos, quedan reflejadas en las disposiciones testamentarias.

Para este primer acercamiento al universo mental del lacianiego durante el Antiguo Régimen, hemos empleado un total de 230 testamentos, todos integrados cronológicamente en el siglo XVIII, y custodiados en el Archivo Histórico Provincial de León ${ }^{15}$. De esos 230 documentos vaciados, 43 son memorias y 13 testamentos conjuntos que, a excepción de un único caso, están protagonizados por matrimonios ${ }^{16}$. Para medir la representatividad de esta fuente no podemos acudir al análisis de los registros parroquiales de la zona, dada su baja calidad. Sin embargo, no tenemos por qué desconfiar de ellos, dado que su volumen no desentona con los trabajos realizados para zonas próximas ${ }^{17}$. Como es natural, esta confianza en la fuente no está reñida con la necesaria prudencia que debemos tener a la hora de realizar afirmaciones demasiado categóricas en un mundo tan complejo como el de las mentalidades.

La primera cuestión a tratar es el estudio de las características de los testadores, tanto desde el punto de vista del género, como del estado civil, el peso socioeconómico o la situación vital a la hora de testar. En el análisis por sexos, nos encontramos prácticamente con un equilibrio entre los testadores masculinos y femeninos, si bien los primeros destacan ligeramente con un 52,2\% frente al 47,8\% de las mujeres. En lo que respecta al estado civil, los casados suponen el 47,9\% del total, los viudos el $33,9 \%$ y los solteros el $18,2 \%$. Sin embargo, esta superioridad de los casados varía considerablemente efectuando un análisis por sexos: en el caso masculino, constituyen el 53,3\%, pero en el femenino, las testadoras solteras y viudas superan claramente a las casadas, suponiendo éstas solamente el 39,1\%. Esta circunstancia puede explicarse por la mayor facilidad de los varones a la hora de contraer segundas nupcias, lo que contribuye al incremento de los casados en

15 A.H.P.L., Protocolos notariales de Murias de Paredes, Escribanos: Gabriel Álvarez, Antonio Álvarez Arroyo, Juan Álvarez Alfonso y Lázaro de Lama. Cajas: 6.544, 6.545, 6.570, 6.571, 6.572, $6.580,6.581,6.582,6.583,6.730,6.731$.

16 Solamente encontramos un testamento conjunto no otorgado por un matrimonio. En él participan el sacerdote D. Cayetano de Sierra y su hermano Pedro, vecinos de Caboalles de Arriba. A.H.P.L., Protocolos notariales de Murias de Paredes, Escribano Antonio Álvarez Arroyo, Caj. 6.581 .

${ }^{17}$ María Consuelo Olano vacía un total de 300 testamentos para todo el siglo XVIII en la villa de Bembibre. Ver, Olano, M ${ }^{\text {a }}$.C. (1986). «Actitud religiosa ante la muerte en la provincia de León en el siglo XVIII: el ejemplo del Bierzo alto». Primeras jornadas de História Moderna. Vol. II. Lisboa: Universidad de Lisboa, pp. 605-623, p. 605. 
nuestro análisis ${ }^{18}$. La explicación puede resultar convincente a la hora de justificar la presencia de un número de viudas tan importante - nada menos que 48-, sin embargo no explica de ninguna manera la también destacada contribución de mujeres célibes -19 casos-. Este importante número de solteras está en relación con las características generales de la familia en la zona. Un número importante de ellas estarían integradas en hogares de tipo complejo, en donde, dadas sus dificultades económicas para formar un agregado doméstico, se veían en la necesidad de vivir a la sombra del mejorado. Tampoco podemos desdeñar la opción solitaria, tanto en solteras como en viudas, si consideramos que ese modo de vida constituía aproximadamente el $10 \%$ de los hogares lacianiegos de la época ${ }^{19}$.

En lo que respecta a la situación socioeconómica de los testadores, la fuente no indica el oficio al que se dedican, circunstancia lógica, habida cuenta del aplastante dominio del sector primario en la zona. Ni siquiera el empleo del título "Don" o "Doña" puede considerarse un signo de verdadera diferenciación social en una comarca marcada por los condicionantes del medio y en la que hasta la pequeña hidalguía se veía obligada a explotar directamente la tierra. Por otro lado, el mayor porcentaje de varones con esa categoría -un 15\% frente al 12,7\% de las mujeresno responde al peso de la pequeña nobleza, sino al papel desempeñado por el clero: 14 de los 18 casos localizados pertenecen a este estamento, jugando un papel poco destacado el clero parroquial frente a los presbíteros vinculados a capellanías de la zona.

Lo que sí detalla claramente la documentación es el estado de salud del testador a la hora de dictar sus últimas voluntades. La inmensa mayoría de ellos las realizan en lo que parece los últimos instantes de su vida, postrados en la cama aquejados de una grave enfermedad. El 86,6\% de los varones y el 83,6\% de las mujeres están en esas circunstancias, porcentajes muy similares a los hallados para el Bierzo $\mathrm{Alto}^{20}$. La amenazadora proximidad de la muerte en la gran mayoría de testamentos acrecienta el valor de la fuente, favoreciendo nuestro análisis de los comportamientos de los montañeses. Esa obsesión por el bien morir, llevaba a algunos de ellos a cubrirse bien las espaldas ante una posible incontinencia verbal en los momentos de agonía que pudiera truncar su camino hacia salvación. Tomás

${ }^{18}$ PÉREZ, Ma.J. (1996). La montaña noroccidental..., p. 273.

${ }^{19}$ PÉREZ, Ma.J. (2004). «Familia y estrategias familiares en el marco de unas estructuras...», p. 131.

${ }^{20}$ No haciendo distinción por sexos, el $85,2 \%$ de los lacianiegos testan en los últimos momentos de su vida, frente al $88,4 \%$ de los bercianos en la segunda mitad del siglo XVIII. Olano, $M^{\text {a }}$.C. (1986). «Actitud religiosa ante la muerte en la provincia de León...», p. 607. 
Ramos, como algunos otros vecinos del concejo, incluían en su testamento una cláusula para evitar cualquier problema al respecto:

"y si acasso por dolencia grave, por persuasión del demonio, halguna cosa dijiere o mostrare contra esto que confieso y creo, lo revoco y anulo, ${ }^{, 21}$.

Un peso ya muy inferior -el $13,8 \%^{22}$ - tienen los testamentos de hombres y mujeres que, no padeciendo una enfermedad grave, deciden testar debido a su edad avanzada. En este caso, la proximidad de la muerte no se hace tan dramática como en el anterior grupo, aunque no por ello desaparece el temor a la condenación eterna. Por último existe un reducido sector de testadores -un $10 \%{ }^{23}$ - que se encuentran en plenitud de facultades físicas a la hora de elaborar sus disposiciones testamentarias. La gran mayoría de estos casos corresponden a testamentos conjuntos en los que, aprovechando la grave enfermedad de uno de los cónyuges, se elabora un documento que asume la pareja.

\section{INVOCACIONES, PROFESIONES DE FE Y PETICIÓN DE INTER- CESORES}

El testamento se inicia con una serie de fórmulas de carácter espiritual. Autores de la talla de Chaunu o Lebrun, han afirmado que, aunque a primera vista este encabezamiento puede parecer poco aprovechable, por ofrecer una imagen excesivamente estereotipada, su análisis seriado nos desvela la permeabilidad de estas fórmulas a las inquietudes espirituales de la época ${ }^{24}$. Según su opinión, ratificada para otros estudios a nivel español, la variedad de encabezamientos que podemos hallar en ese análisis, revela la influencia de los testadores sobre el escribano. No desautorizamos estas afirmaciones para otras zonas más dinámicas desde el punto de vista cultural, especialmente para el mundo urbano, pero, en el caso que nos ocupa, no podemos ni debemos mostrarnos tan optimistas. Hay determinadas partes de este formulario inicial, caso por ejemplo de la invocación, en el que se imponen los criterios del escribano sobre el testador: el análisis interno de la documentación generada por cada escribano revela un notable estatismo roto

${ }^{21}$ Testamento de Tomás Ramos (1700). A.H.P.L., Protocolos notariales de Murias de Paredes, Escribano Juan Álvarez Alfonso. Caja 6.570.

${ }^{22}$ El 6,7\% en los varones y el 9,1\% en las mujeres.

${ }^{23}$ El 5,8\% de los varones y el 5,4\% de las mujeres.

${ }^{24}$ Chaunu, P. (1978): La mort à Paris (16e, 17e, 18e siècles), París: Fayard, p. 233 ; LEBRUn, F. (1971): Les hommes et la mort en Anjou aux 17e et 18e siècles: essai de démographie et de psychologie historiques, París: Mouton, p. 451. 
en muy contadas excepciones, hallándose las principales diferencias, eso sí muy sutiles, en la comparación de los testamentos realizados por distintos notarios. En otros aspectos de este formulario inicial, como por ejemplo en la petición de intercesores, sí que se atisba un mayor protagonismo del testador.

Prácticamente siempre, el formulario se inicia con una invocación a Dios ${ }^{25}$. Durante la primera mitad del siglo, se hace en latín, empleándose generalmente el "In Dei Nomine. Amen", con algunas variaciones sin importancia. Este encabezamiento es muy común en la época para el conjunto español, habiendo sido constatada su presencia mayoritaria en los testamentos de zonas próximas a la estudiada, caso del Bierzo Alto o Asturias ${ }^{26}$. Solamente en algunas memorias de testamento hallamos variaciones significativas que sí pueden responder a una mayor participación del testador. Suelen estar relacionadas con miembros del clero, caso de D. Manuel Martínez Cuerpo, vecino de Ríoscuro, que en 1743 encabezaba su memoria de esta manera: "En el nombre de Dios Nuestro Señor y de la Siempre Virgen María Señora Nuestra"27. Precisamente la incorporación de la Virgen al encabezamiento testamentario se hace norma común a partir de mediados del siglo XVIII, haciéndose referencia tanto a su destacado papel como intercesora de los pecadores ante Dios, como al dogma de la Inmaculada Concepción. La fórmula empleada prácticamente siempre es la misma, no variando entre los escribanos:

"En el nombre de Dios todopoderoso y de la Virgen María su vendita madre y de todos los pecadores avogada, conzevida sin mancha ni sombra de la culpa original desde el primer instante de su ser purísimo y natural. Amen".

Tras la invocación a Dios y la breve exposición de la salud del testador - de la que ya hemos hablado-, éste afirma sus convicciones religiosas, especificando los dogmas y misterios de la fe católica en que cree. De entre todos destaca muy claramente el de la Santísima Trinidad como el más mencionado, apareciendo en el

${ }^{25}$ Solamente en nueve casos no aparece este tipo de encabezamiento. No creemos que dicha omisión sea signo de indiferencia religiosa por parte de los testadores, ya que en todos estos documentos existen disposiciones de tipo devocional -misas votivas, elección de mortaja, ofrendas voluntarias...-. Posiblemente, y dado que en la mayoría de los casos se trata de memorias, sea la premura en dejar por escrito todas las disposiciones del moribundo lo que explique esa ausencia de encabezamiento de corte religioso.

${ }^{26}$ OlAnO, Ma .C. (1986). «Actitud religiosa ante la muerte en la provincia de León en el siglo XVIII: el ejemplo del Bierzo alto». Primeras jornadas de História Moderna. Vol. II. Lisboa: Universidad de Lisboa, pp. 605-623, p. 607; LóPEZ, R. (1985). Mentalidades e ideologías en la ciudad de Oviedo durante el siglo XVIII, Oviedo: Principado de Asturias, p. 52.

${ }^{27}$ A.H.P.L., Protocolos notariales de Murias de Paredes, Escribano Gabriel Álvarez. Caja 6.545. 
$96,1 \%$ de los testamentos (Tabla 1$)^{28}$. El 8,7\% de las veces este misterio aparece sólo, sin referencia a ningún otro, mientras que en un $77 \%$ se le une la poco concreta coletilla "y en todo lo demás que tiene cree enseña y confiessa la Santa Madre Iglesia Católica Apostólica Romana". Esa tan indiscutible hegemonía a lo largo del siglo XVIII, sin variaciones entre los distintos escribanos, nos hace sospechar que, como sucedía con las invocaciones, se trata más de una costumbre que fruto de la implicación directa del testador. De hecho, tenemos constancia de este mismo comportamiento para otras zonas del reino de León o el principado de Asturias $^{29}$. Lo mismo se puede decir de la protestación de la fe, que aparece en la gran mayoría de los documentos consultados -188 de los 230- y que repite siempre la misma fórmula: "vajo cuia fee y creencia e bivido y protesto bibir y morir como católico cristiano".

Tabla 1: Dogmas y misterios mencionados

\begin{tabular}{lrr}
\hline \multicolumn{1}{c}{ Fórmulas empleadas } & Total & $\%$ \\
\hline Santísima Trinidad y todos los demás & 177 & 77,0 \\
Santísima Trinidad & 20 & 8,7 \\
Stma. Trinidad, Encarnación del Verbo y todos los demás & 14 & 6,1 \\
Stma. Trinidad, Inmaculada Concepción y todos los demás & 6 & 2,6 \\
Todos los misterios de la Fe católica & 4 & 1,7 \\
Stma. Trinidad, En. del V., Inmaculada Concepción y todos los demás & 3 & 1,3 \\
Stma. Trinidad, muerte y resurrección de Cristo y todos los demás & 1 & 0,4 \\
Ninguno & 5 & 2,2 \\
\hline Total & 230 & 100,0 \\
\hline
\end{tabular}

FUENTE: Protocolos notariales del Concejo de Laciana

Menos estereotipadas, y por tanto más aprovechables, parecen las menciones a otros dogmas y misterios, como el de la Encarnación, la Inmaculada Concepción de la Virgen o la muerte y resurrección de Cristo. El primero de ellos aparece en 17 casos, el segundo en 9 y el último, solamente en uno, protagonizado por una viuda, vecina de Caboalles de Abajo, que parece mostrar de esta manera su esperanza en la resurrección de la carne, manifestada en el Cristo vencedor de la muerte. Las referencias a la Inmaculada Concepción enlazan con un viejo caballo de batalla de la sociedad española -la defensa de su definición como dogma-, así como también

${ }^{28}$ En el Cádiz de mediados del siglo XVIII lo hacía en el 100\% de los testamentos estudiados. DE La PAscua, Ma .J. (1984). Actitudes ante la muerte en el Cádiz..., p. 96.

${ }^{29}$ RuBio, L. (1987). La Bañeza y su tierra, 1650-1800. Un modelo de sociedad rural leonesa. León: Universidad de León, p. 546; LóPEZ, R. (1985). Oviedo. Muerte y religiosidad..., p. 43; OlANO, Ma .C. (1986). «Actitud religiosa ante la muerte en la provincia de León...», p. 608. 
con las atribuciones de intermediación que tenía la Madre de Cristo. Por último, el misterio de la Encarnación, constituye una de las creencias fundamentales del catolicismo. En cuanto al pequeño número de testamentos sin ninguna referencia al respecto, como es lógico, está más relacionado con la rapidez exigida en las memorias que con un desinterés consciente por parte del testador; de hecho algunos sacerdotes de la zona son protagonistas de estas ausencias.

En prácticamente la mitad de los casos analizados, el 49,6\%, el testador decide confiar su suerte a uno o varios intercesores, con el fin de mejorar su situación antes de su tránsito hacia la otra vida. En este caso sí parece que las opciones personales juegan un papel destacado. Se trata de lograr el mayor apoyo posible en ese difícil camino hacia la gloria eterna, un camino que puede torcerse ante las constantes acechanzas del diablo. Así lo dejaba reflejado en 1730 el testamento de María de Rabanal, vecina de Ríoscuro:

“y para este medio pongo por mi protectora y abogada a la Soberana Reyna de los Ángeles, Madre de Nuestro Redentor Jesuchristo y Señora Nuestra, al Santo Ángel de mi Guarda, Santo de mi nombre y más de mi devoción para que juntos, con todos los cortesanos deel cielo pidan a Dios por mi alma y la encaminen por el verdadero camino de la salvazión y que asi en vida como en muerte me aparten de las tentaciones del demonio y su sombra, ${ }^{, 30}$.

Esta fórmula, en comparación con todas las anteriores, goza de una menor presencia en el discurso testamentario, apreciándose una notable caída en la segunda mitad del siglo XVIII. Algunos autores han identificado ese descenso con el mayor protagonismo que, poco a poco, va cobrando Dios como principal garante de la salvación. En otras palabras: los testadores dejan a un lado a los intermediarios para solicitar directamente la ayuda divina ${ }^{31}$. No olvidemos que en el $93,5 \%$ de todos los testamentos vaciados, el testador encomienda su alma a $\operatorname{Dios}^{32}$. El cierto abandono de los intercesores por parte de los vecinos de Laciana, difiere notablemente de lo observada para la misma época en el Bierzo Alto, en donde esta práctica sigue predominando a lo largo de toda la centuria ${ }^{33}$.

${ }^{30}$ Testamento de María de Rabanal. A.H.P.L., Protocolos notariales de Murias de Paredes, Escribano Gabriel Álvarez. Caja 6.544.

${ }^{31}$ De La PASCuA, Ma..J. (1984). Actitudes ante la muerte en el Cádiz..., p. 102.

32 Esta fórmula se repite sin apenas variaciones a lo largo de todo el siglo XVIII: "Primeramente encomiendo mi anima a Dios Nuestro Señor, pues me la crió y redimió en el estimable tesoro de su preciossa sangre, que se sirva de la perdonar y llebar consigo a la bienaventuranza, que es el fin para que fue criada y el cuerpo a la tierra que fue formado".

33 OLANO, Ma.C. (1986). «Actitud religiosa ante la muerte en la provincia de León...»», p. 609. 
La intercesión más frecuentemente solicitada era la mariana ya que, sin duda alguna, la Virgen, como madre del propio Cristo, ofrecía mayores garantías que el resto de intercesores. Eso explica que aparezca mencionada en el 98,2\% de las ocasiones. En general, no se alude a ninguna advocación en especial, calificándola simplemente como "Reina de los Ángeles". Existe un único caso en el que sí podemos relacionar la petición de una intercesora con las devociones de la zona: en un testamento de 1740, una mujer viuda, vecina de San Miguel, solicitaba la intercesión de Nuestra Señora de las Carreras. Muy por detrás de la Virgen, encontramos la petición como intercesor del santo Ángel de la Guarda, con una presencia del 38,6\%. Su implicación en la defensa del alma en momentos de apuro era lógica, dada su "especialización" en esos menesteres. Algo similar acontecía con el santo del nombre del testador que se invocaba solicitando su ayuda en un $33,3 \%$ de las ocasiones. Además, en un 53,5\% de los testamentos con estas referencias, se optaba por solicitar el auxilio en conjunto de toda la corte celestial. El resto de intercesores jugaban ya un papel muy discreto, con un número de menciones muy limitado: es el caso del santo del día en que se produjera el óbito, San Antonio de Padua o, en una sola ocasión, el santo Cristo de la Veracruz, de Caboalles de Abajo.

\section{LA ELECCIÓN DE LA MORTAJA Y SEPULTURA}

La sección más espiritual del testamento comienza con las disposiciones acerca del entierro. El cuerpo, una vez despojado del alma, no puede ni debe dejarse a su suerte; es necesario buscarle un lugar de reposo adecuado. En zonas urbanas o semiurbanas puede existir un interesante abanico de posibilidades. No sucedía lo mismo en Laciana, puesto que la inexistencia de conventos o monasterios en sus límites, restringía las posibilidades de elegir lugar de enterramiento únicamente a la parroquia del testador. Dentro de la iglesia parroquial, empero, sí que se podía optar por diversas posibilidades que quedan reflejadas en la documentación vaciada. Poco más de la mitad de los testadores, concretamente un 51,7\%, optaban por elegir ellos mismos el lugar de sepultura dentro del templo. El resto lo dejaban al criterio de sus albaceas. Curiosamente, dentro de este grupo sin disposiciones personales, encontramos a la gran mayoría de los sacerdotes localizados, que solían confiar en el criterio de su párroco tanto a la hora de elegir su última residencia en la Tierra, como para el resto de disposiciones vinculadas a su entierro, remitiéndose muchas veces a las constituciones sinodales del obispado de Oviedo.

Los sectores más pudientes de la sociedad lacianiega optan por sepultarse en sus propias capillas familiares, marcando de esta manera las distancias con el resto del vecindario incluso a la hora de abandonar la vida terrena. Así, el matrimonio compuesto por D. Tomás Arias y $\mathrm{D}^{\mathrm{a}}$. Catalina Bluz, vecinos de Ríoscuro, decidían 
depositar sus cuerpos "en nuestra capilla que tenemos en esta parroquia". La viuda $\mathrm{D}^{\mathrm{a}}$. Francisca González del Campillo disponía ser enterrada "en la capilla del maiorazgo de la cassa en que bibo" o la también viuda María Gómez, vecina de Orallo, indicaba "que mis carnes sean sepultadas en la capilla que tiene Don Pedro Gómez mi hermano al lado del ebangelio en la iglesia parrochial de Santa Marina de esta dicho lugar" ${ }^{34}$. De todos modos, este tipo de enterramientos de carácter privado eran escasos: solamente hemos localizado 11 casos. El resto de los lacianiegos se tenían que conformar con una situación más o menos preferente dentro de la iglesia parroquial. Un 9,2\% optaban por una sepultura en la capilla mayor, el lugar más privilegiado del templo, con un contacto más directo con el Santísimo. Dado que se trata de las sepulturas más caras, es lógico pensar que, en la mayoría de las ocasiones, eran los sectores más desahogados económicamente los que se decidían por esa opción. Otro 5,9\% optaba por el enterramiento en las proximidades del altar de alguna devoción particular, caso de San Antonio de Padua o, sobre todo, de la Virgen del Rosario, en el caso de los vecinos de Robles.

Hay también algunos casos muy puntuales en los que primaba la familiaridad con alguna zona del templo o algún tipo de creencia personal que se nos escapa: así observamos como dos mujeres decidían por enterrarse bajo el lugar donde escuchaban habitualmente la misa o como un varón optaba por hacerlo en las proximidades de la pila bautismal de su parroquia. Hay también un grupo de cierta importancia, componen el 35,5\% del total, en el que parece que predominaban los criterios afectivos de carácter familiar sobre los religiosos: en veinticinco testamentos el otorgante disponía enterrarse junto a sus padres, en diez prefieren acompañar a su cónyuge y en otros siete prefieren a otros familiares cercanos -un hijo, un hermano...-. El resto de testadores se distribuyen por otros lugares del templo parroquial, primando las sepulturas de precios medios y no existiendo diferencias reseñables ni en cuanto al comportamiento por sexos ni desde el punto de vista temporal. La falta de testimonios referidos a los sectores menos pudientes de la sociedad, explica la ausencia de referencias a enterramientos en los atrios, lugar común para los más pobres.

Otro de los aspectos más relevantes dentro del ritual vinculado a la muerte, era la elección de un hábito o mortaja. En el concejo de Laciana, el 43,5\% de los otorgantes dejaban estipulada la prenda a vestir en el momento del entierro. Sin embargo, este porcentaje puede resultar engañoso, ya que realizando un análisis evolutivo a lo largo del XVIII, descubrimos notables diferencias entre la primera y

${ }^{34}$ A.H.P.L., Protocolos notariales de Murias de Paredes, Escribano Gabriel Álvarez. Cajas 6.544 y 6.545. Escribano Juan Álvarez Alfonso. Caja 6.572. 
la segunda mitad de la centuria. Durante los cincuenta primeros años esta práctica solamente aparece reflejada en el 11,3\% de los testamentos, casi todos relacionados con el sector socioeconómico más pudiente o con el clero. En la segunda mitad de la centuria, empero, se aprecia un notabilísimo cambio de comportamiento, aumentando el porcentaje hasta el $87,6 \%$. Desde nuestro punto de vista, este progreso de la mortaja debe estar íntimamente relacionado a una creciente influencia pastoral del relativamente próximo convento de San Francisco de Tineo. Hay varios indicios que apuntan en este sentido: en primer lugar, la mortaja franciscana monopoliza todos los casos detectados, excepción hecha de cuatro testamentos de clérigos que optan por sus vestiduras sagradas ${ }^{35}$. Además, en algunos de los documentos manejados, se hace una referencia expresa a la influencia de aquel cenobio asturiano de frailes menores: en el testamento conjunto de Pedro Rivas y su esposa Dominga García, el matrimonio solicitaba que se les amortajase con "el ábito de Nuestro Padre San Francisco de Tineo"36.

Este predominio del hábito franciscano en Laciana no resulta, de todos modos, sorprendente puesto que esa prenda era, por aquellos años, la mortaja más empleada en la práctica totalidad del territorio español ${ }^{37}$, constatándose asimismo un comportamiento muy similar en otras zonas ya estudiadas del propio reino de León $^{38}$. Las razones de este predominio estaban, en primer lugar, relacionadas con el prestigio de la propia Orden Franciscana y de su santo fundador, considerado por muchos como el mayor imitador de Cristo. Pero, como apunta González Lopo, sin duda eran las indulgencias que derivaban de su uso el principal atractivo para los

${ }^{35}$ Uno de ellos incluso combina esas vestiduras sacras con el hábito de San Francisco.

${ }^{36}$ A.H.P.L., Protocolos notariales de Murias de Paredes, Escribano Lázaro de Lama. Caja 6.730.

${ }^{37} \mathrm{El} 60 \%$ de los testadores gaditanos del siglo XVIII se decantaban por el hábito franciscano. En Oviedo ese porcentaje subía hasta el $68^{\prime} 2 \%$. En Sevilla variaba del $71 \%$ a comienzos de la centuria al $51 \%$ a finales. En Málaga rondaba el 57\% y en Santiago de Compostela suponía el $86 \%$ del total entre 1751 y 1760. El peso del hábito franciscano en Tui o en el ámbito rural de la Galicia occidental era también muy considerable. De LA PASCUA, Mà.J. (1984). Actitudes ante la muerte en el Cádiz..., p. 265; LóPEZ, R. (1985). Oviedo. Muerte y religiosidad..., p. 65; RIVAS, J.A. (1986). Miedo y piedad: testamentos sevillanos del siglo XVIII. Sevilla: Diputación de Sevilla, p. 119; GonZÁLEZ, D. (1989). «La mortaja religiosa en Santiago entre los siglos XVI y XIX». Compostellanum, pp. 271-295, p. 276; GONZÁLEZ, D. (1984). «La actitud ante la muerte en la Galicia occidental de los siglos XVII y XVIII». EIRAS, A., (Dir.). La documentación notarial y la historia. Salamanca: Universidad de Santiago. (2 Vols.), pp. 125-137, Vol. II. 102.

${ }^{38}$ RuBIO, L. (1987). La Bañeza y su tierra ..., p. 458; OLANO, Mª.C. (1986). «Actitud religiosa ante la muerte en la provincia de León...», p. 613. RUBIO, L. (1986): «Estructura social y mentalidad religiosa-colectiva en la ciudad de León durante los siglos XVII y XVIII», Revista Internacional de Sociología, p. 609-646, p. 625. 
fieles $^{39}$. La directa relación, entre indulgencia y reducción efectiva de días de estancia en el Purgatorio, convertían a la mortaja franciscana en un valioso instrumento para lograr una muerte digna y un pasaporte adecuado para el otro mundo. Los privilegios concedidos por Roma eran, desde luego, muy importantes:

"Los que se mandan enterrar con el hábito de nuestro Padre San Francisco ganan indulgencia plenaria, concedida por León X, y basta para ganarla solo pedirle, aunque no se le vistan hasta después de su muerte" 40

En este sentido, el hábito se convertía en una de las muchas "seguridades" de salvación que buscaba el hombre del Antiguo Régimen, en la misma línea de otras ya analizadas como querer enterrarse en las cercanías de un determinado altar o encomendarse a la Virgen o a los santos. Pero estas no eran las únicas razones; los sectores acomodados de la sociedad veían en la mortaja franciscana un medio para relacionarse, en el momento crucial de la muerte, con los pobres, que representaban San Francisco y sus sucesores ${ }^{41}$. Era un intento de acercamiento de última hora a una austeridad de la que nada habían querido saber durante la vida ${ }^{42}$. Como acertadamente comenta el profesor Barreiro Mallón, la carencia de un conocimiento profundo de las verdades de la fe llevaban al hombre a apelar a estas muestras externas de alivio a sus angustias sobre el dilema de la salvación ${ }^{43}$.

\section{EL ENTIERRO Y LOS SUFRAGIOS}

La mortaja significaba pues un firme aliado para hacer frente a los múltiples peligros que acechaban al alma en el momento del tránsito hacia la otra vida, pero no era el único recurso. El otorgante del testamento buscaba otra serie de seguridades para facilitar la tan ansiada salvación. Acompañando al moribundo en sus últimos instantes de vida se hallaba, normalmente, el cura párroco de la feligresía que, además, conducía la comitiva fúnebre desde la residencia del difunto hasta el lugar del funeral y entierro. Para estimular el interés del párroco en estas labores existía la llamada "oferta voluntaria", una ofrenda generalmente en especie,

39 GonzÁLEZ, D. (2002). Los comportamientos religiosos en la Galicia del Barroco. Santiago: Xunta de Galicia, pp. 285-384.

${ }^{40}$ ANÓNIMO. (1825). Indulgencias, gracias y privilegios de la Venerable Orden Tercera de Penitencia de Nuestro Seráfico Padre San Francisco. Santiago: Imprenta de Manuel de Vila, p. 31.

${ }^{41}$ BARREIRO, B. (1984). «La nobleza asturiana... », p. 35.

${ }^{42}$ REY, O. (1981). «El clero urbano compostelano a fines del siglo XVII: mentalidades y hábitos culturales»». EIRAS, A. y otros. La historia social de Galicia en sus fuentes de protocolos. Santiago: Universidad de Santiago, pp. 485-519.

${ }^{43}$ BARREIRO, B. (1984). «La nobleza asturiana... », p. 35. 
que intentaba asegurar lo que, en la práctica, era ya una obligación del clérigo. La desconfianza hacia su profesionalidad hacía que en un número importante de testamentos se estipulase claramente las obligaciones a las que estaba sujeto el párroco para recibir aquel presente: en 1728, Isidro García Piñero, vecino de Caboalles de Abajo, ofrecía "medio magueto que ba a dos años con una fanega de centeno, con la precisa obligazión de que mi pastor y parrocho me asista y acompañe hasta que me aparte de la vida caduca a la sempiterna" ${ }^{\prime 4}$.

La oferta voluntaria era una práctica muy extendida en el concejo de Laciana durante todo el siglo XVIII: más de la mitad de los otorgantes, concretamente el $61,7 \%$, dejaban estipulada esta donación en sus testamentos. No existen apenas diferencias entre sexos -el porcentaje en las mujeres está ligeramente por encima de la media, alcanzando el 63,6\%, mientras que en los varones se queda en el 60\%, pero sí parece que se aprecia un cierto abandono de esta práctica a partir de la segunda mitad de la centuria: si en los primeros cincuenta años del siglo XVIII el $71,3 \%$ de los testamentos analizados incluían esa oferta, a partir de entonces el porcentaje desciende hasta el $50,9 \%$. Esta fuerte implantación de la oferta voluntaria en la Montaña noroccidental leonesa contrasta con la escasa incidencia que tenía en la época para otras zonas del obispado de Oviedo. Buena parte de esa reducida fuerza estaba relacionada con la pretensión que el clero asturiano tenía de transformarla en una carga obligatoria, como queda reflejado en la versión manuscrita del sínodo de 1769. Sin embargo, el Consejo de Castilla cambió sin previa consulta esas disposiciones para la versión impresa, señalando que tales ofrendas habían de ser "voluntarias en la cantidad y calidad", y que "a ningún feligrés se le obligue a semejantes oblaciones" ${ }^{45}$. En cuanto al monto de la donación, variaba dependiendo del poder adquisitivo del testador, aunque, en general, la oferta consistente en una fanega de pan de centeno y una cántara de vino es la más repetida. Hay, no obstante, un $19,7 \%$ de testamentos en los que a esa ofrenda de pan y vino se le añade una cabeza de ganado bovino. Las limosnas en dinero eran, por el contrario, muy escasas.

Además de con el párroco, generalmente, los vecinos de Laciana buscaban reforzar las ceremonias fúnebres con un mayor número de clérigos seculares, puesto que la ausencia de conventos y monasterios en las inmediaciones, impedía a los regulares acceder al mercado funerario. Para este aspecto contamos con la

44 Testamento conjunto de Isidro García Piñero y D $D^{\text {a }}$. María Méndez de la Vega. A.H.P.L., Protocolos notariales de Murias de Paredes, Escribano Gabriel Álvarez. Caja 6.544.

${ }^{45}$ LÓPEZ, R. (1985). Mentalidades e ideologías..., p. 106; (1786) CONSTITUCIONES sinodales del obispado de Oviedo. Lib. I, Tít. V, Const. I y Lib. III, Tít. X, Const. IV. 
información aportada por el $56,1 \%$ de los testamentos consultados. El resto no ofrecen datos, pues en ellos los testadores confiaban los pormenores de los actos religiosos a sus albaceas. Lógicamente, la carencia de información, no implica la ausencia de clérigos en esos funerales, sino única y exclusivamente la imposibilidad de conocer su número. La gran mayoría testamentos que contienen disposiciones en torno al entierro, un $65 \%$, optan por la convocatoria del mayor número de clérigos que pudiera reunirse (Tabla 2). Esta solicitud implicaba un desembolso económico notable que parece remitirnos a la infravaloración en la fuente de los sectores socioeconómicos más pobres, a lo que hay que añadir también ese importante porcentaje de ocultación referido. De tener un mayor número de casos con información, posiblemente, se produciría una disminución de la importancia de este grupo, pues al tratarse de una disposición muy específica es más fácil que quede reflejada en la documentación que otras más comunes.

Tabla 2: Sacerdotes empleados en el entierro

\begin{tabular}{|c|c|c|}
\hline Número de clérigos & Total & $\%$ \\
\hline De 3 a 5 & 10 & 7,8 \\
\hline De 6 a 8 & 24 & 18,6 \\
\hline De 9 a 12 & 11 & 8,5 \\
\hline Todos los que puedan juntarse & 84 & 65,1 \\
\hline Total & 129 & 100,0 \\
\hline
\end{tabular}

FUENTE: Protocolos notariales del Concejo de Laciana

Junto a los clérigos necesarios para rogar por el alma del difunto, los testadores consideraban también de inestimable ayuda el auxilio espiritual de sus vecinos. Se intentaba estimular la concurrencia del mayor número de ellos a los actos fúnebres mediante el recurso de la ofrecer bebida e incluso comida, a cambio de una oración por su alma. El 56,1\% de los lacianiegos así lo señalaban en su testamento ${ }^{46}$; Pedro Álvarez, vecino de Rabanal de Arriba, estipulaba en el suyo de 1732 que se repartiese "por amor de Dios un pellexo de vino el día de mi entierro según se acostumbra azer en otros tales días" o, unos años antes, en 1700, Pedro Loerno, señalaba que se diese de "comer a mis feligreses el día de mi entierro" deferencia más común para con los vecinos era la invitación exclusivamente a beber, que aparece en el $85,6 \%$ de los casos analizados; las invitaciones a comer suponían el 3\%, mientras que las que combinaban comida con bebida alcanzaban el

${ }^{46}$ El 54,2\% de los varones y el 58,2\% de las mujeres.

${ }^{47}$ A.H.P.L., Protocolos notariales de Murias de Paredes, Escribano Gabriel Álvarez. Caja 6.544; Escribano Juan Álvarez Alfonso, Caja 6.570. 
$11,4 \%$. La ausencia de bienes con que costear esta gratificación podía traer como consecuencia el desesperado llamamiento a la solidaridad de los vecinos pobres, como queda reflejado en el testamento de la soltera María Álvarez, vecina de Villager:

" $y$ el día de mi entierro suplico a todos mis vezinos y demás fieles crisptianos asistan a enterrar mi cadáver, que por ser pobre de solemnidad no tengo medios para dejarles caridad de vino a los que llegasen a encomendarme a Dios",48.

El lugar de la invitación variaba dependiendo del testador: generalmente se desarrollaba delante de la iglesia parroquial, una vez concluido el acto, aunque en ocasiones, como en el caso de Diego de Ribas del Sil, vecino de Villablino, se señalaba como lugar y momento más propicio "al tiempo de salir mi cadáver de casa" $^{\text {"49 }}$. D. Pedro Buelva Lorenzana, sacerdote vecino de San Miguel, renegaba de esa práctica, prefiriendo orientar aquel gasto económico a caridades para los vecinos pobres del entorno ${ }^{50}$. Pese a esta condena por parte del clérigo, la práctica se mantuvo sin apenas variación a lo largo del siglo XVIII, apreciándose incluso un ligero progreso durante la segunda mitad de la centuria, momento en el que acapara el $58,3 \%$ de los testamentos de esa etapa frente al $54,1 \%$ de la primera.

También progresó significativamente el número de testadores integrados en alguna cofradía y que, por ende, se beneficiaban de la solidaridad de sus hermanos, manifestada tanto en su acompañamiento hasta el lugar de sepultura como en las obligaciones religiosas para con el difunto. De este modo, podía aumentar considerablemente el número de sacerdotes asistentes al sepelio, dada su importante presencia en estas asociaciones religiosas. El porcentaje de testadores cofrades pasó de un $9,8 \%$ en la primera mitad del siglo XVIII al $28,7 \%$ en la segunda. A cambio de las muestras de solidaridad recibidas y del firme apoyo a su ánima a través de la oración, el hermano fallecido debía corresponder con las obligaciones económicas estipuladas en las ordenaciones de la cofradía y que estaban generalmente relacionadas con el ofrecimiento de una colación a los hermanos.

48 A.H.P.L., Protocolos notariales de Murias de Paredes, Escribano Lázaro de Lama. Caja 6.731.

49 A.H.P.L., Protocolos notariales de Murias de Paredes, Escribano Gabriel Álvarez. Caja 6.545.

50 "Y es mi voluntad que el día de mi entierro, en lugar de caridad de vino, que yo llamo abuso, se dé de comer y veber a los pobres que concurran y entre ellos se repartan cien reales de limosna". A.H.P.L., Protocolos notariales de Murias de Paredes, Escribano Antonio Álvarez Arroyo. Caja 6.581 . 
La presencia de pobres en el entierro y las limosnas que podían disfrutar en ese día señalado, tienen una doble interpretación, perfectamente compatible para la época $^{51}$. Por un lado buscaban una mayor proximidad a Dios a través de los marginados, siguiendo al pie de la letra la doctrina evangélica. Por otro, también existía una cierta carga de ostentación, de la misma manera que sucedía, una vez sepultado el cadáver, con el encargo de misas. No es sorprendente pues que los seis casos hallados correspondan a clérigos o a integrantes del sector más acomodado de la sociedad lacianiega. En la comarca parece primar la limosna al acompañamiento del féretro. Así Pedro Gómez, vecino de Orallo, ordenaba simplemente que se diesen "tres baras de paño de sayal" a tres pobres de su parroquia $^{52}$, mientras que un sacerdote de Robles ofrecía de limosna una fanega de trigo para los vecinos más desfavorecidos de su parroquia. Otros, como D. Pedro Vuelta, presbítero de Orallo, señalaba que "a los pobres mendicantes que concurriesen a encomendarme a Dios se les dé de comer a todos los expresados al estilo del Pays, sin exceder y acavada esta función a la puerta de mi casa a los expresados pobres solamente se les dé un real para que prosigan a encomendarme a Dios" ${ }^{, 53}$. Pero, sin duda alguna, el que mostró un mayor interés por el ceremonial fue D. Alonso Gómez Vuelta, vecino de San Miguel, que dejaba ordenado en su testamento "que an de acompañar mi entierro seis pobres deste lugar, vestidos de paño baviano, como se usa en la tierra, saio y calzón"

Otro indicador de la actitud de una sociedad ante la muerte es el análisis de todas las ceremonias relacionadas con ella, al margen del entierro y funerales ${ }^{55}$. Tanto las llamadas "misas por una vez" como las perpetuas, son un recurso más para la obtención de gracias espirituales, para la vida después de la muerte. El ofrecimiento de una o varias misas por el alma del difunto es una práctica que procede de los primeros años del cristianismo y que aún hoy en día se mantiene

${ }^{51}$ Otro tipo de caridad pero, en esta ocasión obligatoria, eran las denominadas "mandas forzosas". Dado ese carácter forzoso y la escasa información aportada por los testamentos de Laciana, su análisis no resulta de ningún interés.

52 A.H.P.L., Protocolos notariales de Murias de Paredes, Escribano Juan Álvarez Alfonso. Caja 6.571 .

53 A.H.P.L., Protocolos notariales de Murias de Paredes, Escribano Antonio Álvarez Arroyo. Caja 6.582.

${ }^{54}$ A.H.P.L., Protocolos notariales de Murias de Paredes, Escribano Lázaro de Lama. Caja 6.730.

${ }^{55}$ Las escasas referencias en las fuentes a responsos, cabos de año y otros tipos semejantes de ceremonias religiosas están relacionadas con su fuerte implantación en la zona que hace innecesario recordarlo en los testamentos. El escribano simplemente señala que todos esos actos se deben hacer "como es costumbre" sin ofrecernos más información. 
vigente. Desde el punto de vista cualitativo es pues esa función profundamente religiosa la explicación de la vigencia de esta práctica. Sin embargo, el número de misas encargadas puede responder no sólo a creencias religiosas sino también a otros criterios más mundanos: las misas tienen unos estipendios que satisfacer, por lo que el número de misas encargado no sólo está relacionado con las creencias del otorgante sino también con su propio nivel adquisitivo. Además, pueden existir motivos vinculados al prestigio social. La muerte es el broche final de la vida terrena y, por tanto, el modo de morir estaba íntimamente relacionado con la manera de vivir. Las mandas más impresionantes, con miles de misas, fundaciones pías, etc., se correspondían en la época con sectores sociales de gran relevancia nobleza, alto clero, burguesía acomodada...-. En Laciana, ya lo señalamos, las diferencias socioeconómicas no estaban tan marcadas como en el mundo urbano, por lo que no aparece ni una sola manda de esas dimensiones. El 92,6\% de testamentos con información válida muestran como el discreto poder adquisitivo de los lacianiegos se manifiesta en un menor número de misas por una vez solicitadas. Mientras que en la ciudad de Oviedo la media se encontraba en 227,6 misas por testador, en Laciana se reducía a 101,7. Otro dato revelador es que el $62,9 \%$ de los otorgantes encargan menos de cien misas (Tabla 3).

Tabla 3: Misas de ánima encargadas por los testadores

\begin{tabular}{lrr}
\hline \multicolumn{1}{c}{ Número de misas } & Total & $\%$ \\
\hline 300 o más & 8 & 3,8 \\
De 200 a 299 & 15 & 7,0 \\
De 100 a 199 & 56 & 26,3 \\
De 50 a 99 & 104 & 48,8 \\
De 15 a 49 & 30 & 14,1 \\
\hline Total & 213 & 100,0 \\
\hline
\end{tabular}

Fuente: Protocolos notariales del Concejo de Laciana

En cuanto a la tipología de estas misas, las referencias halladas son más bien escasas. En general, los testadores estipulaban exclusivamente su número, dejando a criterio de los albaceas el lugar y fecha de celebración. Hay, no obstante, casos en los que se señala. Domingo García del Potro, vecino de Ríoscuro, dejaba estipuladas 40 misas por su alma "y destas es mi voluntad se digan veinte en la parroquia donde mi cadáver sea sepultado y las demás en la parroquia de Ravanal" ${ }^{156}$. En otras ocasiones, se aprovechan esas misas de ánima para realizar además una obra de caridad con el clero mercenario: en 1748, Domingo de la

${ }^{56}$ A.H.P.L., Protocolos notariales de Murias de Paredes, Escribano Gabriel Álvarez. Caja 6.544. 
Llama "el más viejo", vecino de Sosas, encargaba ciento cincuenta misas "atendiendo a sazerdotes capillanes pobres a que deven ser preferidos a los párrocos". Algo similar solicitaba cuatro años más tarde Pedro Gancedo, vecino de Villablino ${ }^{57}$. Más abundantes eran los treintenarios dispuestos para celebrar en algún convento más o menos próximo, o en centros urbanos como Oviedo o León: en total aparecen un total de catorce testamentos con este tipo de disposiciones. María Piñero, vecina de San Miguel de Laciana indicaba que "se digan por mi alma treinta misas en el combento de mi padre San Francisco de Tineo", además de "otras treinta repartidas por los santuarios y hermitas de la maior devoción que parezca a mis testamentarios" ${ }^{, 58}$. Por su parte, D. Manuel Martínez Cuerpo, cura de Ríoscuro, encargaba doscientas, "de las quales se se an de dezir cinquenta en en el combento de San Francisco de Tineo, cinquenta en los carmelitas de Ponferrada, cinquenta en los descalcicos de León y las otras cinquenta a disposición de dichos sus testamentarios" ${ }^{\prime 59}$. Posiblemente debido a su proximidad a la zona, el convento franciscano de Tineo, con nueve casos hallados, era el más beneficiado por estos encargos de misas, seguido, con cuatro, por el cenobio de San Froilán de León, también de franciscanos, aunque descalzos. El resto de conventos representados jugaban ya un papel más modesto ${ }^{60}$.

$\mathrm{Si}$ en las misas por una vez no se aprecian diferencias significativas en su evolución a lo largo del siglo XVIII, en las perpetuas sí que existen notables cambios: el porcentaje de testadores que disponen sobre esta cuestión pasa del $34,4 \%$ durante la primera mitad de la centuria a solamente el $14,8 \%$ en la segunda. La caída, también apreciada en ámbitos relativamente cercanos -caso, por ejemplo, de Oviedo- parece estar relacionada más con criterios económicos que con una pérdida de sentido religioso. A fin de cuentas tanto las misas perpetuas como las oficiadas por una vez, buscaban el mismo objetivo espiritual. El problema se encontraba pues en las mayores dificultades que se podían encontrar a finales de la centuria para garantizar, a través de los bienes que los sustentaba estas fundaciones perpetuas de misas ${ }^{61}$. En consecuencia, solamente las economías más sólidas

${ }^{57}$ A.H.P.L., Protocolos notariales de Murias de Paredes, Escribano Lázaro de Lama. Caja 6.730 y 6.731 .

${ }^{58}$ A.H.P.L., Protocolos notariales de Murias de Paredes, Escribano Gabriel Álvarez. Caja 6.544.

59 A.H.P.L., Protocolos notariales de Murias de Paredes, Escribano Gabriel Álvarez. Caja 6.545.

${ }^{60}$ Hay dos referencias al convento de Santo Domingo de Oviedo, y una a los conventos de San Francisco de Villafranca y el Carmen de Ponferrada, así como al monasterio de San Juan de Corias (orden de San Benito) y a la colegiata de San Isidoro de León.

${ }^{61}$ LÓPEZ, R. (1985). Mentalidades e ideologías..., p. 133. 
podían asegurar la perpetua carga que implicaba una fundación de este tipo ${ }^{62}$. En la Montaña noroccidental, los bienes sobre los que se tomaban los estipendios de las misas perpetuas eran, en la totalidad de los casos analizados, los inmuebles, fundamentalmente prados y tierras de cultivo. Había también algunos casos en los que los fundadores relacionaban directamente la misa con los bienes vinculados, forzando a través de una cláusula a los herederos el cumplimiento estricto de esas disposiciones religiosas.

\section{LA RELIGIOSIDAD DE LOS MONTAÑESES: COFRADÍAS Y MISAS VOTIVAS}

Los protocolos notariales en general y los testamentos en particular, suponen un interesante instrumento de medición, tanto de las devociones específicas del pueblo durante la época, como del desarrollo del asociacionismo religioso. Para este último aspecto habría sido de mayor utilidad recurrir a documentación directa, como la parroquial -libros de visitas y libros de cofradías, fundamentalmente-. Por desgracia, la pérdida de los fondos más importantes de ese tipo, nos obliga a basarnos en el análisis exclusivo de los protocolos, lo cual plantea innegables dificultades. Afortunadamente, contamos con el trabajo de la profesora Pérez Álvarez sobre las cofradías de la comarca de Omaña. Sin duda esta aportación facilita nuestro análisis a través de la comparación de comportamientos ${ }^{63}$.

Como ya hemos señalado, los testamentos parecen indicar un progresivo crecimiento del asociacionismo religioso seglar en la sociedad lacianiega: si en los primeros cincuenta años del siglo XVIII los testadores cofrades significaban solamente el 9,8\%, durante la segunda mitad de siglo el porcentaje subió hasta el $28,7 \%$. Es posible que esta mayor presencia de cofradías esté relacionada con un fuerte proceso pastoral paralelo, protagonizado tanto por el clero secular como por el regular -los franciscanos de Tineo o las misiones de otras órdenes religiosas-. De hecho, el desarrollo de la mortaja franciscana en la segunda mitad de siglo parece corroborar nuestras impresiones. Aún así, es necesario abrir el abanico de fuentes y el espacio temporal de nuestro análisis para convertir esta hipótesis en una afirmación con cierta fiabilidad. Por otro lado, los varones parecen estar más

${ }^{62}$ Las referencias a la situación socioeconómica del otorgante es muy limitada: de los 58 localizados, sabemos que 10 de ellos usaban el título de Don o Doña, cinco de los cuales eran clérigos. Por sexos la paridad es prácticamente completa: un $25,8 \%$ de los varones frente a un $24,5 \%$ de las mujeres.

63 PÉREZ, M.J. (1997). «Las cofradías en la Montaña de León: canal de expresión del fervor popular». Actas del Simposium Religiosidad popular en España. pp. 47-55, Vol. I. 
implicados en estos movimientos asociativos religiosos que las mujeres: aparecen 31 cofrades masculinos frente a 16 femeninos.

Las cofradías reflejadas en la documentación son tres: la de Ánimas es la que más cofrades integra, con 24 en total. Es posible que se trate de más de una cofradía de esa devoción, puesto que la extensión territorial que engloba la residencia de sus hermanos así parece hacerlo entender. Desde luego, sabemos de la existencia de una cofradía de Ánimas en Ríoscuro porque así lo refieren varios testadores ${ }^{64}$. Parece que en San Miguel existía otra, si atendemos a lo que señalaba en 1787 su vecino Manuel Rubio, que aseguraba ser cofrade de Ánimas "deste lugar" ${ }^{\prime 65}$. Contamos también con cofrades vecinos de otras entidades sin más referencias, caso por ejemplo de los de Caboalles, que puede significar o bien la existencia en aquellas parroquias de sendas cofradías de esta devoción o de su desplazamiento a la más cercana para los cultos propios. Sea como fuere, parece que la devoción a las Ánimas del Purgatorio estaba bastante extendida por la Montaña Noroccidental leonesa. Esta cofradía, lógicamente, estaba muy orientada a los cultos en torno a la muerte. Los cofrades de Ánimas acompañaban al hermano difunto a su última morada, rogando por su alma, y en compensación, solían recibir una comida a su cuenta. Así lo estipulaba el cofrade José Álvarez, vecino de Caboalles de Arriba ${ }^{66}$ y así lo señalaban también las ordenaciones de la cofradía de Ánimas de la vecina Omaña ${ }^{67}$.

Aunque la segunda de las hermandades en cuanto a número de integrantes, con 17, se puede catalogar como de devoción mariana, lo cierto es que también desempeñaba un papel importante como marco de solidaridad para los actos fúnebres y la encomendación del alma. En efecto, la cofradía de Nuestra Señora de las Carreras, desempeñaba esa doble función, por otro lado, muy común en todo este tipo de asociaciones religiosas de la época. Muy por detrás en cuanto a representación, con sólo 3 casos localizados, se encontraba otra cofradía de

${ }^{64}$ Andrés Álvarez, vecino de Sosas y cofrade de Ánimas, encargaba en su testamento de 1751 una misa en el altar de las Ánimas de Ríoscuro. A.H.P.L., Protocolos notariales de Murias de Paredes, Escribano Lázaro de Lama. Caja 6.731.

65 A.H.P.L., Protocolos notariales de Murias de Paredes, Escribano Antonio Álvarez Arroyo. Caja 6.581.

66 A.H.P.L., Protocolos notariales de Murias de Paredes, Escribano Antonio Álvarez Arroyo. Caja 6.582 .

${ }^{67}$ A cambio de la colación acostumbrada, la cofradía celebraba una misa por la redención del alma del difunto. Además, todos los cofrades estaban obligados a asistir al entierro y funeral del hermano, perdonándose la impuntualidad siempre y cuando estuviesen presentes en el momento de la encomendación de su alma. PÉREZ, Ma.J. (1997). «Las cofradías en la Montaña de León...», p. 53. 
devoción particular, la de "la vendita Magdalena, sita en el lugar de Cuevas", como señalaba Francisca de Ribas, vecina de Rabanal de Arriba ${ }^{68}$. Por último, contamos con otros 3 casos en los que el testador no desvela la cofradía o cofradías a las que pertenecía, limitándose simplemente a pedir que sus hermanos acudiesen a acompañarlo en su sepelio. Además, aparecen otros 2 vecinos de la zona integrados en la tercera orden franciscana seglar, un movimiento religioso que vivía un proceso de fuerte implantación en la Corona de Castilla desde comienzos del siglo $\mathrm{XVII}^{69}$. Su adscripción a este movimiento se explica, en uno de los casos, por la influencia del vecino convento franciscano de Tineo: Matías Álvarez Carballo, de Villaseca, ofrecía en 1785 cincuenta misas en aquel cenobio "donde soy hermano" $"$. En el otro, es consecuencia de los desplazamientos migratorios hacia la villa y corte de Madrid, perfectamente constatados para la época y que, como veremos, también tendrán consecuencias en el mundo devocional. Manuel Casquete, vecino de Caboalles de Abajo, en su testamento del mismo año, confirmaba su pertenencia a una de las fraternidades terceras más influyentes de todos los territorios de la Corona, concediéndole una importante cantidad de dinero tras su muerte:

"y es mi boluntad que mediante soy hermano de nuestro padre San Francisco el Grande de Madrid que quando se inbie abiso de mi fallecimiento se dé y remita a dicho conbento zien ducados de vellón para que aquella benerable religión me encomiende a Dios "71.

Las misas votivas encargadas por los testadores lacianiegos, nos abren las puertas al descubrimiento del mundo devocional de la zona durante el siglo XVIII. Hemos aglutinado las 1.524 referencias localizadas en seis grupos, atendiendo a su diferente tipología (Tabla 4). Las advocaciones marianas son las claras dominadoras de este panorama, circunstancia perfectamente comprensible, habida cuenta de la nueva dimensión que cobró este culto en el mundo católico tras la reforma de Trento ${ }^{72}$. La devoción a la Virgen está fragmentada en un enorme abanico de advocaciones, de entre las que destacan muy claramente, tres

68 A.H.P.L., Protocolos notariales de Murias de Paredes, Escribano Antonio Álvarez Arroyo. Caja 6.580.

${ }^{69}$ Martín, A. (2005). Religión y sociedad en Ferrolterra durante el Antiguo Régimen. La VOT seglar franciscana. Salamanca: Ayuntamiento de Ferrol, pp. 26 y ss.

${ }^{70}$ A.H.P.L., Protocolos notariales de Murias de Paredes, Escribano Juan Álvarez Alfonso. Caja 6.571 .

71 A.H.P.L., Protocolos notariales de Murias de Paredes, Escribano Antonio Álvarez Arroyo. Caja 6.581.

${ }^{72}$ RÉAU, L. (2000). Iconografía del arte cristiano. Barcelona: Ediciones del Serbal, p. 547. 
genuinamente locales: Nuestra Señora del Rosario, Nuestra Señora de las Carreras y la Virgen de Carrasconte. Estas tres advocaciones suponen el $47 \%$ del total de las marianas. La del Rosario, sita en la parroquial de Robles, destaca por encima de las demás, con 114 menciones. Esta advocación está estrechamente relacionada con la extensión de las prácticas religiosas rosarianas que, en el caso español, comenzaron a calar profundamente entre las clases populares a partir de la segunda mitad del siglo XVII. Además, la Virgen del Rosario se presentaba como abrigo de las Ánimas del purgatorio y amparo de pecadores, por lo que su influencia en los cultos en torno a la muerte está fuera de toda duda ${ }^{73}$. Por su parte, la de Carreras, ya lo vimos, contaba en el siglo XVIII con una importante cofradía que, por un lado, refleja su fuerte impronta en la zona y, por otro, contribuiría eficazmente al desarrollo de su culto. Por fin, la de Carrasconte era objeto de una importante romería popular que ha llegado hasta nuestros días ${ }^{74}$. Durante el siglo XVIII el culto a la Virgen debió de vivir un proceso de expansión, cuya muestra más evidente es la construcción de un nuevo y espacioso templo, finalizado en $1781^{75}$. También aparecen un 17,6\% de referencias a advocaciones marianas situadas fuera del ámbito geográfico montañés: la mayoría de ellas eran objeto de culto en espacios territoriales relativamente próximos, caso de las bercianas advocaciones de la Peña y la Encina, las asturianas de Rei Casto y Covadonga, o la leonesa del Camino $^{76}$. También la Virgen de Guadalupe, con 22 casos localizados, entraría dentro de este grupo. Posiblemente esta advocación, con fuerte peso en Extremadura y en el virreinato de Nueva España, llegó a la montaña leonesa a través de las rutas de la trashumancia.

73 Romero, C. (1989). «El fenómeno rosariano como expresión de la religiosidad popular en la Sevilla del Barroco»». Álvarez, L.C., Buxó, M.J. y Rodríguez, S. (Coords.). La religiosidad popular. Barcelona: Anthropos, Vol. II, pp. 540-553, p. 543; Trens, M. (1947). María. Iconografía de la Virgen en el arte español, Madrid: Plus Ultra, pp. 262-263.

74 Dice la copla: "Virxe de Carrasconte/Carrascontina/que'ntre Babia y Chaciana/t'hachas mitida”. Alonso, J. (2001). «El patrimonio etnográfico». Álvarez, C. y Alonso, J. (Coords.). Guía del patrimonio cultural de las comarcas de Cuatro Valles (Legado histórico, arqueológico, artístico y etnográfico). León: Asociación Cuatro Valles, pp. 125-180, p. 152.

75 MorÁIS, E. «La arquitectura religiosa, casas blasonadas y puentes». Álvarez, C. y Alonso, J. (Coords.). Guía del patrimonio cultural..., pp. 75-100, p. 87.

${ }^{76}$ La Virgen de la Peña cuenta con 28 menciones, la de la Encina 22, Rey Casto y Camino 11 y Covadonga 2. 
Tabla 4: Devociones reflejadas en las misas votivas de Laciana

\begin{tabular}{lrr}
\hline & Tipo de devoción & $\%$ \\
\hline Mariana & 640 & 42,0 \\
Santos & 499 & 32,7 \\
Cristológica & 169 & 11,1 \\
Ángel de la Guarda & 109 & 7,2 \\
Santo de su nombre & 76 & 5,0 \\
Dios y Trinidad & 31 & 2,0 \\
\hline Total & 1.524 & 100,0 \\
\hline
\end{tabular}

FUENTE: Protocolos notariales del Concejo de Laciana

Entre los santos, la diversidad de menciones y el peso de las devociones locales se hace aún más evidente. Junto a los patrones de las diferentes parroquias del entorno -San Miguel, Santa María Magdalena, San Julián, San Andrés...-, destacan las menciones a San Antonio de Padua, San Roque y las Ánimas del purgatorio ${ }^{77}$. Del desarrollo de esta última devoción ya hemos hablado, destacando la fuerte implantación de las cofradías de Ánimas en la zona. Por su parte, el santo franciscano, gozaba en la España del siglo XVIII de gran fama como "milagrero", sobre todo a través de su responso, eficacísimo -según la opinión de los contemporáneos- en momentos de grave peligro o enfermedad. Además, San Antonio había cobrado un destacado papel en determinados ámbitos, caso del vecino reino de Galicia, como rescatador de Ánimas del purgatorio. La presencia del culto al santo en la zona se manifiesta en la erección de ermitas como la de Robles. También San Roque contaba con algún que otro pequeño templo de fundación popular, como el que existía en Llamas.

Las devociones de corte Cristológico están claramente dominadas por las advocaciones pasionales: de las 149 menciones localizadas, solamente 22 no se relacionaba con esa temática ${ }^{78}$. Las referencias a imágenes del entorno lacianiego son mayoritarias, destacando como las más frecuentes las misas votivas al Cristo de la Veracruz, que contaba con ermita propia en Caboalles de Abajo, al de la Misericordia de Robles y al de San Mamed de las Rozas. Estas tres referencias

${ }^{77}$ Estas tres devociones suponían el 32,5\% de las menciones a santos en la zona. San Antonio contribuía con 59 menciones, San Roque con una menos y las Ánimas con 45.

78 Se trata de una referencia al "Niño Jesús", otra al "Dulce Nombre de Jesús" y 22 a San Salvador. 
suponen el $50,3 \%$ del total ${ }^{79}$. Del $23,1 \%$ de referencias foráneas, destacaban las relacionadas con el Ecce Homo de Bembibre y el Santo Cristo del Amor de Portaceli. El templo del primero se hallaba en el Bierzo y, por tanto, dentro de una lógica zona de intercambio de devociones. Sin embargo, el segundo está relacionado con el importante peso de la emigración lacianiega hacia la villa y corte, en donde se encontraba el convento que albergaba aquella venerada imagen. Finalmente, las referencias al Ángel de la Guarda y al santo de nombre del testador, están más relacionadas con cultos vinculados a la muerte que con devociones cotidianas. Lo mismo se puede decir de las misas encargadas bajo el patrocinio de la Santísima Trinidad, el dogma católico, como vimos, más abundantemente repetido en los testamentos.

${ }^{79}$ El Cristo de la Veracruz aparece mencionado en 36 ocasiones, el de la Misericordia en 28 y el de Rozas en 21. 
